\title{
Message from the President of ASI-2009
}

\section{R. P. Srivastava}

\section{Vasant Panchmi}

\section{Fellow Members,}

On the day of Saraswati Puja I write this message to all esteemed members. The goddess of learning and knowledge is kind enough to bless us. The ASI celebrated well attended North Zonal CME at AIIMS between 23-25th January. The I.J.S. has already made quality inroads into scientific publication under the ever-active leadership of Dr. S. K. Shukla, the editor and his editorial board team. Our publisher Springer is providing quality presentation. The HQ has involved itself in ensuring posting of I.J.S. issues and that has resulted in near total delivery.

As this message is the first one of the tenure of the new team, let me share with you that the good work started by previous team will continue along with new ideas making its impact. The website is being updated and there is all efforts by Prof. Arvind Kumar to update the directory. Dr. Srihari Dhorepatil is finding ways and means to raise the membership. The Uttarakhand chapter is formed while Chhattisgarh gets the status of full chapter. Please raise membership more and more. This year the efforts are on to open overseas chapters in Great Britain and Irelend as well as USA. This will provide interface for our membership to come closer to members overseas. The national

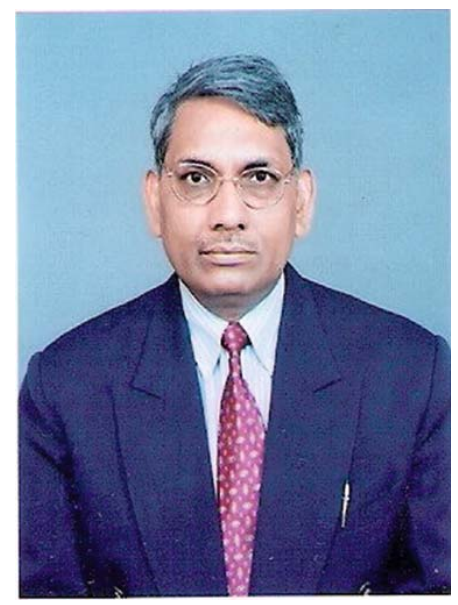

legal support committee and national family social security scheme are being drafted and you will hear about them soon. I am aware that the count down of the tenure has begun and I have a journey of miles to go.

Please use the email ID's of president2009asi@gmail.com and presidentelectasi@gmail.com to communicate liberally with concerned officials.

The ASICON is on the threshold of being labelled poor on academics. Efforts are on, and I assure you that with the current council members and the ASICON 2009 organising team we will usher in quality change and hold our heads high for academic contents of the ASICON as well.

The HQ is activating zonal CMEs in the first half of the year, while second half will be dedicated for sectional and chapter annual activities.

Please keep a watch and participate to contribute and benefit from academic activities and social events of the ASI!

A newsletter will follow telling you details of proposed activities.

Long Live ASI!

Each one, find one, get one to raise membership.

Sanghe Shakti Kalyuge.

\section{R. P. Srivastava $(\bowtie)$}

$\mathrm{Kd} / 13$, City Centre, Sector 4,

Bokaro Steel City - 827 004,

Jharkhand,

India

E-mail: rpsbko@gmail.com

$\mathrm{Ph}:+91$ / 6542 / 232632, 232111

Fax: $+91 / 6542$ / 259500 